\title{
Pregnancy outcome in women with heart disease at a tertiary referral teaching center in Northern India
}

\author{
Kavita Gahlot ${ }^{1}$, Punya Pratap Singh ${ }^{2}$, K. Pandey ${ }^{3}$
}

\begin{abstract}
${ }^{1}$ Department of Obstetrics and Gynaecology, ${ }^{2}$ Department of Radiodiagnosis, B.M.C, Sagar, Madhya Pradesh, India ${ }^{3}$ Department of Obstetrics and Gynaecology, G.S.V.M. Medical College, Kanpur, Uttar Pradesh, India
\end{abstract}

Received: 07 July 2016

Accepted: 05 August 2016

\section{*Correspondence: \\ Dr. Kavita Gahlot, \\ E-mail: drpunya@gmail.com}

Copyright: ( ) the author(s), publisher and licensee Medip Academy. This is an open-access article distributed under the terms of the Creative Commons Attribution Non-Commercial License, which permits unrestricted non-commercial use, distribution, and reproduction in any medium, provided the original work is properly cited.

\begin{abstract}
Background: Pregnancy causes a significant burden on cardiovascular system due to hemodynamic changes therefore a diseased heart may not be able to adjust with extra load resulting in heart failure and even maternal mortality.

Methods: A prospective study was done in 50 women with heart disease over a period of 12 months from 2010 to 2011 at G.S.V.M. Medical College, Kanpur. At the first antenatal visit baseline data is recorded included age, parity, gestational age, NYHA class, co-morbid conditions, prior cardiac events, cardiac lesion (if already diagnosed), prior surgery/interventions, cyanosis and medications. A thorough clinical examination and investigations were done.

Results: Maximum numbers of patients (56\%) were in the age group 20-24 years. $52 \%$ of patients were primigravida and $48 \%$ of patients were multigravida. Maximum numbers of patients $(76.67 \%)$ were in the lower socioeconomic group. Chronic rheumatic heart disease $(84 \%)$ was the most common type of heart disease followed by congenital cardiac disease (14\%). Heart disease if diagnosed preconceptionally or during earlier period of gestation both maternal $(8.9 \%)$ and foetal complications $(22.8 \%)$ are lesser as compared to patients in whom diagnosis was made late. There is also the significant difference with majority of the foetal complications in group IV (80\%) (preterm birth, IUGR and perinatal mortality) as compared to group I (14.2\%).

Conclusions: Maternal and perinatal outcome in women with heart disease depends mainly on the functional cardiac status during pregnancy, the risk being greater in NYHA III and IV. Our study shows that surgical intervention or medical management in pregnancy improves the functional class and also improves the maternal and fetal outcomes. Interventions can only be successfully done either before pregnancy or during $2^{\text {nd }}$ trimester. When patients were diagnosed before pregnancy we have enough time for counseling and treatment. Counseling further increase the compliance and acceptance for medical and surgical interventions.
\end{abstract}

Keywords: Heart disease, Maternal mortality, Neonatal mortality, NYHA, Rheumatic heart disease, Congenital heart disease

\section{INTRODUCTION}

Pregnancy causes a significant burden on cardiovascular system due to hemodynamic changes therefore a diseased heart may not be able to adjust with extra load resulting in heart failure and even maternal mortality. Actual risk depends on the type and severity of the particular heart disease.
Cardiac disease complicates $1 \%$ to $4 \%$ of pregnancies. Despite of continuous advancement in treatment and management of cardio-vascular diseases, it accounts for one third of maternal mortality along with it increases the risk of adverse maternal and foetal outcome. ${ }^{1}$

With the availability of modern surgical facilities and advances in medical management (due to advanced equipment and better drugs) along with intensive 
maternal and fetal monitoring the scenario has quite changed.

This study was done with the aim to assess the maternal and fetal outcomes in patients of heart disease with early diagnosis and timely surgical or medical intervention compared to patient with late diagnosis and no interventions.

\section{METHODS}

A prospective study was done in 50 women with heart disease over a period of 12 months from 2010 to 2011 at G.S.V.M. Medical College, Kanpur. At the first antenatal visit baseline data is recorded included age, parity, gestational age, NYHA class ,comorbid conditions, prior cardiac events, cardiac lesion(if already diagnosed), prior surgery/interventions, cyanosis and medications. A thorough clinical examination and investigations were done. 17 patients were diagnosed before pregnancy and 33 were diagnosed during pregnancy out of which 14 patients diagnosed during $1^{\text {st }}$ and $2^{\text {nd }}$ trimester while 14 patients diagnosed during $3^{\text {rd }}$ trimester and remaining 5 were diagnosed during labour. No. of patients with RHD were $42(84 \%)$ followed by congenital heart disease i.e. 7 (14\%), one patient was of dilated cardiomyopathy.

\section{RESULTS}

Table 1 describes the social and demographic characteristics of the patients with heart disease. Maximum numbers of patients $(56 \%)$ were in the age group 20-24 years. $52 \%$ of patients were primigravida and $48 \%$ of patients were multigravida.

Table 1: Sociodemographic profile of study group.

\begin{tabular}{|lll|}
\hline Age & No. & $\%$ \\
\hline $15-19$ & 3 & 6 \\
\hline $20-24$ & 28 & 56 \\
\hline $25-29$ & 16 & 32 \\
\hline $30-34$ & 6 & 12 \\
\hline Parity & \\
\hline Primigravida & 26 & 52 \\
\hline Multigravida & 24 & 48 \\
\hline Socioeconomic status & & \\
\hline High & 3 & 6 \\
\hline Middle & 10 & 10 \\
\hline Low & 17 & 34 \\
\hline
\end{tabular}

Maximum numbers of patients $(76.67 \%)$ were in the lower socioeconomic group. Chronic rheumatic heart disease $(84 \%)$ was the most common type of heart disease followed by congenital cardiac disease (14\%). One patient was of dilated cardiomyopathy. Among rheumatic heart disease mitral valve involvement was the most common (Table 2).
Table 2: Distribution of patients according to type of lesion.

\begin{tabular}{|lll|}
\hline & No. of cases $(\mathbf{N}=50)$ & $\%$ \\
\hline MR & 3 & 6 \\
\hline$M S$ & 28 & 56 \\
\hline$M S+M R$ & 16 & 32 \\
\hline$M R+M S+A R$ & 6 & 12 \\
\hline$M R+M S+T R$ & & \\
\hline$M S+A R+T R$ & 26 & 52 \\
\hline ASD & 24 & 48 \\
\hline VSD & & \\
\hline COA & 3 & 6 \\
\hline DCM & 10 & 10 \\
\hline
\end{tabular}

MR - Mitral regurgitation; MS- Mitral stenosis; TRTricuspid regurgitation; AR- Aortic regurgitation; AS Aortic stenosis; ASD - Atrial septal defect; VSD Ventricular septal defect; COA - Coarctation of aorta; DCM Dialated cardiomyopathy; This table shows that among valvular heart disease Mitral stenosis was the predominant lesion in most of the patients; MS + MR were the commonest valvular lesion found in the $40 \%$ of cases; Among congenital heart disease ASD was the most common lesion i.e. $30 \%$.

Table 3: Distribution of patients according to time of diagnosis and maternal, fetal complications.

\begin{tabular}{|c|c|c|c|c|}
\hline \multirow[t]{2}{*}{$\begin{array}{l}\text { Time of } \\
\text { diagnosis }\end{array}$} & \multicolumn{2}{|c|}{$\begin{array}{l}\text { Early diagnosis* } \\
(\mathbf{n}-\mathbf{3 1})\end{array}$} & \multicolumn{2}{|c|}{$\begin{array}{l}\text { Late diagnosis*** } \\
(\mathbf{n}-19)\end{array}$} \\
\hline & No. & $\%$ & No. & $\%$ \\
\hline \multicolumn{5}{|l|}{ Maternal } \\
\hline $\begin{array}{l}\text { Congestive } \\
\text { heart failure }\end{array}$ & 2 & 6.4 & 6 & 31.5 \\
\hline Arrhythmia & - & & 1 & 5 \\
\hline Mortality & 1 & 3.5 & 4 & 21 \\
\hline \multicolumn{5}{|l|}{ Fetal } \\
\hline Preterm & 4 & 12.9 & 6 & 31.5 \\
\hline $\begin{array}{l}\text { Small for } \\
\text { gestational age }\end{array}$ & 1 & 6.4 & 6 & 31.5 \\
\hline $\begin{array}{l}\text { Perinatal } \\
\text { mortality }\end{array}$ & 2 & 3.5 & 3 & 14 \\
\hline
\end{tabular}

*Early diagnosed group - patient diagnosed before pregnancy and during $1^{\text {st }}$ and $2^{\text {nd }}$ trimester; $* *$ Late diagnosed group patient diagnosed during $3^{\text {rd }}$ trimester or in labour.

Table 3 demonstrates that heart disease if diagnosed preconceptionally or during earlier period of gestation both maternal $(8.9 \%)$ and foetal complications $(22.8 \%)$ are lesser as compared to patients in whom diagnosis was made late i.e. $3^{\text {rd }}$ trimester or during labour (maternal $57 \%$, foetal - $77 \%$ ). Table 4 shows that no maternal complications occurred in patients in whom surgical intervention in form of (valvotomy-15, valve replacement-3, ASD patch closure, cardioversion-1, PDA correction 1) were done and these patients tolerated pregnancy well. Out of these 21 patients with surgical interventions, 19 interventions were done before pregnancy and two were done during $2^{\text {nd }}$ trimester. Group II included the compliant patients with medical intervention and complications were observed only in 
form of congestive heart failure in $13.3 \%$ patients but with no maternal mortality. Group III included the noncompliant patients with medical intervention and complications were observed in form of congestive heart failure (18\%), arrhythmia (9\%), and maternal mortality (9\%). Group IV included the patients with no medical or surgical intervention and complications were maximum in form of congestive heart failure (40\%), arrhythmia $(10 \%)$, and maternal mortality $(30 \%)$. There is also the significant difference with majority of the foetal complications in group IV $(80 \%)$ (preterm birth, IUGR and perinatal mortality) as compared to group I (14.2\%).

Table 4: Maternal and fetal outcome in patient with medical and surgical interventions.

\begin{tabular}{|c|c|c|c|c|c|c|c|c|}
\hline & \multicolumn{2}{|c|}{ Group -1 } & \multicolumn{2}{|c|}{ Group - 2} & \multicolumn{2}{|c|}{ Group - 3} & \multicolumn{2}{|c|}{ Late diagnosis } \\
\hline & No. & $\%$ & No. & $\%$ & No. & $\%$ & No. & $\%$ \\
\hline \multicolumn{9}{|l|}{ Maternal } \\
\hline Congestive heart failure & - & & 2 & 13.3 & 2 & 18 & 4 & 40 \\
\hline Arrhythmia & - & & - & & 1 & 9 & 1 & 10 \\
\hline Mortality & - & & 1 & 6.6 & 1 & 9 & 3 & 30 \\
\hline \multicolumn{9}{|l|}{ Fetal } \\
\hline Preterm & 2 & 14.2 & 2 & 13.3 & 3 & 27 & 3 & 30 \\
\hline Small for gestational age & - & & 2 & 13.3 & 3 & 27 & 3 & 30 \\
\hline Perinatal mortality & - & & 1 & 3.5 & 1 & 9 & 2 & 20 \\
\hline
\end{tabular}

Group - 1 = Patients with surgical intervention; group - 2 = Patients with medical management and compliant; Group $-1=$ Patients with medical management and non - compliant; Group - $1=$ Patients newly diagnosed nearly at term or in labour; *Mortality in 5 patients $-4=$ Due to congestive heart failure and $1=$ arrhythmia.

Table 5: Materanal and fetal outcome in relation to NYHA class.

\begin{tabular}{|c|c|c|c|c|c|c|c|c|}
\hline & \multicolumn{2}{|c|}{ NYHA -I } & \multicolumn{2}{|c|}{ NYHA -II } & \multicolumn{2}{|c|}{ NYHA -III } & \multicolumn{2}{|c|}{ NYHA -IV } \\
\hline & No. & $\%$ & No. & $\%$ & No. & $\%$ & No. & $\%$ \\
\hline \multicolumn{9}{|l|}{ Maternal } \\
\hline Congestive heart failure & - & & 2 & 5.7 & 3 & 18 & 3 & 50 \\
\hline Arrhythmia & - & & - & & 1 & 9 & 1 & 16.6 \\
\hline Mortality & - & & 1 & 3.5 & 2 & 9 & 2 & 33.3 \\
\hline \multicolumn{9}{|l|}{ Fetal } \\
\hline Preterm & 1 & 20 & 5 & 17.8 & 2 & 27 & 2 & 33.3 \\
\hline Small for gestational age & - & & 4 & 14.2 & 3 & 27 & 1 & 16.6 \\
\hline Perinatal mortality & - & & 1 & 3.5 & 1 & 9 & 2 & 33.3 \\
\hline
\end{tabular}

Table 5 describes the relationship between maternal and foetal complications including mortality according to NYHA class i.e. severity of the maternal heart disease. No maternal complications occurred in NYHA class I where as $50 \%$ of patients had congestive heart, failure in NYHA class IV. Maternal mortality (33\%) was significantly increased in NYHA class IV. Foetal complications were found to be more in NYHA class IV $(82 \%)$ as compared to class I $(20 \%)$.

\section{DISCUSSION}

At our centre during a period of 12 months the prevalence of heart disease was $1.13 \%$ which was in correlation with the study done by Asghar $\mathrm{F}$ et al $(0.98 \%){ }^{2}$ Rheumatic heart disease is still the most common heart disease in our country followed by congenital heart disease Bhatla $\mathrm{N}$ et al. ${ }^{3}$ The ratio of rheumatic heart disease to congenital heart disease in our study was 4:1. Mitral stenosis (MS) was the predominant lesion in many studies Hameed A et al, Sawhney $\mathrm{H}$ et al, Asghar F et al being $69.6 \%, 89.2 \%$ and $42 \%$ respectively. ${ }^{1,2,4}$ In our study also MS was predominant in $50.6 \%$ of the cases. Early detection, evaluation and prevention of precipitating factors are important in reducing complications.

The functional class has a direct bearing on both the maternal and foetal outcome. $34 \%$ of the women in our study were in NYHA class III and IV compared to $22.3 \%$ in a series by Sawhney $\mathrm{H}$ et al. ${ }^{4}$ Congestive cardiac failure was seen in 8 women $(16 \%)$ as compared to $38 \%$ in the series by Hameed A et al and $20 \%$ in the study by Asghar $\mathrm{F}$ et al, arrhythmia was seen in $4 \%$ of cases, maternal mortality $10 \%$, of which occurred in NYHA class III and IV ,this was in correspondence with Sawhney $\mathrm{H}$ et al who reported a maternal mortality rate of $2 \%$, of which occurred in NYHA class III and IV. Overall cardiac complication rate in our study was $15.62 \%$ which is very similar to $13 \%$ reported by Siu SC et al. ${ }^{1,2,4,5}$ 
In our study $85.4 \%$ of the women had vaginal delivery as compared to $86 \%, 91.42 \%$, and $92 \%$ in other studies Hameed A et al, Sawhney $\mathrm{H}$ et al, Asghar $\mathrm{F}$ et al. ${ }^{1,2,4}$ Caesarean section (14.6\%) was done mainly for obstetric indications. Forceps and ventouse assisted deliveries were performed in $16.2 \%$ patients. Any form of cardiac surgery during pregnancy is avoided untill unless the cases are refractory to all type of medical treatment. Percutaneous balloon mitral valvotomy is less invasive and is safe and effective during pregnancy. Maternal complications were significantly reduced (18\% versus $60 \%$ ) in patient with medical or surgical interventions as compared to patients with noncompliant or diagnosed late in pregnancy this was in correspondence with study reported by Nercolini et al and Arnoni et al. ${ }^{6,7}$ All the women improved by at least one functional class by surgical intervention, compared to $82 \%$ in the Chandigarh study Sawhney $\mathrm{H}$ et al. ${ }^{4}$ Elkayam et al has concluded that, PBMV should be done in severe symptomatic women with MS who do not respond to medical therapy. ${ }^{8}$

Preterm labour was seen in $20 \%$ in our study. The corresponding incidence in other studies was 14\% Asghar $\mathrm{F}$ et al, $12 \%$ Sawhney $\mathrm{H}$ et al and $23 \%$ Hameed $\mathrm{A}$ et al. ${ }^{1,2,4}$ In our study, small for gestational age was seen in $16 \%$ compared to $18.2 \%$ Sawhney $\mathrm{H}$ et al and $21 \%$ Hameed A et al in others. ${ }^{1,4}$ There was a significant difference in the perinatal outcome between NYHA class I, II and III, IV in our study. The perinatal mortality rate in our series was $3.5 \%$ in class I and II compared to $14 \%$ in class III and IV. The perinatal mortality in study done by Sawhney et al was $2 \%$ in NYHA class I and II and $8 \%$ in class III and IV. Foetal complications $(22.8 \%$ versus $77 \%$ ) were significantly reduced in patient with medical or surgical interventions as compared to patients who were noncompliant or diagnosed late in pregnancy this was in accordance with Pratibha et al. ${ }^{1,4,9}$

\section{CONCLUSION}

Maternal and perinatal outcome in women with heart disease depends mainly on the functional cardiac status during pregnancy, the risk being greater in NYHA III and IV. Our study shows that surgical intervention or medical management in pregnancy improves the functional class and also improves the maternal and fetal outcomes. In view of the high risk of low birth weight, preterm delivery, intrauterine growth restriction, IUD and still birth, antenatal foetal surveillance becomes mandatory and should be offered to these women with heart disease. Management of valvular heart disease during pregnancy is challenging. A thorough knowledge of the expected natural history of the disease during pregnancy and of the possible treatment options is required for clinical decision making. Surgical interventions can only be successfully done either before pregnancy or during $2^{\text {nd }}$ trimester.
When patients were diagnosed before pregnancy we have enough time for counselling and treatment. Counseling further increase the compliance and acceptance for medical and surgical interventions which results in optimal outcome of the pregnancy for the mother and the baby.

\section{ACKNOWLEDGEMENTS}

Authors would like to thank Dr. Sikha Pandey, Dr. Nidhi Mishra, Dr. Sheela Jain and Dr. Sona Singh as consultant in Department of Obstetrics And Gynaecology, B.M.C., Sagar to guide in preparing this menucript. Authors also acknowledge Mr. Indal Singh for his assistance in statistical work.

Funding: No funding sources

Conflict of interest: None declared

Ethical approval: The study was approved by the Institutional Ethics Committee

\section{REFERENCES}

1. Hameed A, Karaalp IS, Tummala PP, Wani OR, Canetti M, Akhter MW, et al. The effect of valvular heart disease on maternal and fetal outcome of pregnancy. J Am Coll Cardiol. 2001;37:893-9.

2. Asghar F, Kokab H. Evaluation and outcome of pregnancy complicated by heart disease. J Pak Med Assoc. 2005;55:416-9.

3. Bhatla N, Lal S Behera G, Kriplani A, Mittal S. Agrawal N, et al. Cardiac disease in pregnancy. Int $\mathbf{J}$ Gynaecol Obstet. 2003;82(2):153-9.

4. Sawhney H, Aggarwal N, Suri V, Vasishta K, Sharma Y, Grover A. Maternal and perinatal outcome in rheumatic heart disease. Int J Gynaecol Obstet. 2003;80:9-14

5. Siu SC, Sermer M, Colman JM, Alvarez AN, Mercier LA, Morton BC, et al. Prospective multicenter study of pregnancy outcomes in women with heart disease. Circulation. 2001;104:515-21.

6. Nercolini D, Guerios EE, Bueno R, Tarastchuk J, Andrade P, Pacheco A, et al. Mitral stenosis and percutaneous mitral valvuloplasty (part-I). J Invasive Cardiol. 2005; 17:382-6.

7. Arnoni RT, Arnoni AS, Bonini RC, de Almeida AF, Neto CA, Dinkhuysen JJ, et al. Risk factors associated with cardiac surgery during pregnancy. Ann Thorac Surg. 2003;76:1605-8.

8. Elkayam U, Bitar F. Valvular heart disease and pregnancy, part I - native valves. Am J Coll Cardiol. 2005;46:223-30.

9. Rani DP, Vani NG, Kiranmai D, Usha V. Pregnancy outcome in chronic rheumatic heart disease. J Obstet Gynecol India. 2009;59(1):41-6.

Cite this article as: Gahlot K, Singh PP, Pandey

$\mathrm{K}$. Pregnancy outcome in women with heart disease at a tertiary referral teaching center in Northern India. Int J Reprod Contracept Obstet Gynecol 2016;5:3056-9. 